Doc. dr. Izet Terzić

\title{
DŽEMALUDDIN EL-AFGANI, REFORMATOR ISLAMSKE MISLI
}

Sažetak

Riječi Allahovog poslanika Muhammeda, s.a.v.s., Učenjaci su nasljednici Božijih poslanika imaju punu potvrdu u liku i djelu Džemaludina Afganija. Od djetinjastva on iskazuje interesovanje $i$ ljubav prema nauci i filozofiji. Iz toga se izrodila jedna veoma snažna $i$ utjecajna ličnost koja je zdravom razumu stavila pod lupu tadašnje vlastodršce $i$ učenjake. Hrabro ulazi u dijalog sa svakim autoritetom vlasti i nauke. Na putu ostvarenja Istine ne štedi nikoga, pa čak ni samoga sebe, zbog čega se može reći da je i svoj život položio za te uzvišene ciljeve.

Iako je bio oštar kritičar mnogih političkih $i$ vjerskih lidera, kako u islamskim tako $i$ u neislamskim sredinama, uživao je njihovo puno poštovanje i uvažavanje. Uzvišeni ciljevi se mogu postići samo mudrim potezima uz pomoć Gospodara svjetova.

Afganija će ostati upamćen kao najsvjetlija baklja koja se pojavila u drugoj polovini devetnaestog vijeka, a njegove mudre ideje ni danas ne gube na svojoj snazi i značaju.

Uvod

Za porijeklo Džemaluddina El-Afganije i danas se otimaju njegovi biografi iz raznih islamskih zemalja - Irana, Indije i Afganistana - želeći svaki za sebe prigrabiti čast suotadžbinstva sa Afganijem, iako njegovo ime El-Afgani, kao i njegovo svjedočenje pribilježeno rukom najvjernijeg sljedbenika Muhammeda Abduhua nedvojbeno govore da potiče iz Afganistana. ${ }^{1}$ Međutim, njegova aktivnost bila je rasprostranjena po svim islamskim zemljama i svaka od njih je tako bila njegov dom, a ni evropske prijestonice nisu mu

${ }^{1}$ Vidi: Rašid Bilalić, "Preporod", br. 5, Starješinstvo islamske zajednice BiH, Hrvatske i Slovenije, Sarajevo, 1. III 1982. 
bile strane, niti je on bio stranac u njima. Sklapao je poznanstva sa učenjacima, teolozima i dostojnim političarima Istoka i Zapada.

Manji broj biografa spominje mjesto njegovog rođenja Hemdan u Iranu, dok je većina na stanovištu da je Džemaluddin porijeklom Afganistanac. ${ }^{2}$ Zabilježeno je i to da je jednom prilikom Džemaluddin rekao da je prva zemlja koju je dotaklo njegovo tijelo Afganistan. ${ }^{3}$ S obzirom da je napisao i jedno djelo pod nazivom Kraća povijest Afganistana i to nas navodi da potvrdimo kako ne bi uopće trebalo biti dvojbe o njegovom porijeklu.

Rođen je u Esad Abadu, nedaleko od Kabula, 1838. godine. Prvo obrazovanje stekao je u Afganistanu i Perziji. Kada je imao 18 godina, ispoljio je izuzetan interes za znanost i filozofiju. Godinu i po provodi u Indiji, gdje se upoznaje sa evropskim znanostima, a zatim posjećuje Mekku i obavlja hadž. Po povratku u Afganistan slijedila je decenija njegove političke aktivnosti, prekidane promjenljivošću građanskog rata. Zbog svojih liberalnih ideja i popularnosti među narodom stječe neprijateljstvo emira Šir Ali-hana, povodom čijeg dolaska na vlast, uz pomoć Engleza, Afgani napušta zemlju 1868. godine.

Potom odlazi u Indiju, gdje od naroda biva dobro primljen, ali i tu ga vlasti sprečavaju da održava kontakte sa ulemom i narodom. Mjesec dana nakon dolaska u Indiju engleske vlasti ga brodom upućuju za Suec, a odatle u Kairo, gdje provodi 40 dana.

Poslije ove kratke posjete Egiptu, Džemaluddin odlazi u Istanbul, gdje isto tako biva izvanredno primljen i gdje razvija svoju aktivnost. Međutim, zbog razilaženja u stavovima ubrzo dolazi do sukoba sa šejhul-islamom i službenom ulemom, te sultan od njega, umjesto nastavljanja dijaloga, traži da napusti zemlju. Afgani ponovo dolazi u Egipat 1871. godine i biva toplo primljen u intelektualnim krugovima, te odlučuje da produži boravak. Osam narednih godina provedenih u Egiptu njegove su najplodnije godine.

Dolaskom na vlast vladara Teufika, Afgani biva ponovo protjeran i sproveden u Indiju, gdje mu engleske vlasti sprečavaju kretanje dok ne uguše Urabijevu revoluciju u Egiptu, 1882. godine. U

2 Vidi: Selam Medkur, 'Džemaluddin El-Afgani', El-Medžlisul-e'ala lišuunilislamijjeti, Vizaretu evkaf, Kairo, 1962, str. 12.

${ }^{3}$ Vidi: Muhammed Seid Abdulmedžid, ' Nabigatuš-šerk es-sejjid Džemaluddin ElAfgani', Darul-kitabil-arebi, Kairo, 1967, str. 7. 
Indiji Džemaluddin piše raspravu Erreddu ala eddehrijjin, a potom, 1883. odlazi u Pariz, gdje mu se pridružuje i Muhammed Abduhu. U Parizu izdaju sedmične novine El-Urwetul-wuska, u kojima pozivaju muslimane na otpor kolonizaciji. Međutim, Englezi brzo zabranjuju unošenje novina u Egipat i Indiju, tako da poslije osamnaestog broja prestaju sa izlaženjem. I pored kratkog vijeka novine su izvršile vidan i značajan uticaj na sve one koji su ih čitali.

Iz Pariza Afgani odlazi nakratko u London, a zatim vrijeme provodi u Rusiji. Iz Rusije posjećuje Minhen, gdje se nalazi sa iranskim šahom Nasir Ed-Dinom, koji ga poziva da dođe u Iran. Poslije upornog nagovaranja odlazi u Teheran 1890. godine. Ubrzo dolazi do ponovnog razilaženja između šaha i Džemaluddina i taj konflikt završava prognanstvom iz Irana 1891. godine. Ponovo, nakon Irana, Džemaluddin čini kratku posjetu Londonu, da bi svoj bogati revolucionarni put završio prihvatanjem poziva sultana Abdulhamida da dođe u Istanbul i pomogne sprovođenju islamske reforme. Izgleda da je to bio samo trik kojim se sultan poslužio kako bi stalno imao na oku Afganijevo kretanje. Tu, u Istanbulu, od 1892. godine je ostao sve do svoje smrti, 9. marta 1897. godine.

U jednom tako kratkom prikazu životnog puta pisca risale erreddu ala eddehrijjin mogli smo vidjeti da je svojim obrazovanjem i putovanjem po Indiji, Iranu, Iraku, Egiptu, Hidžazu, Njemačkoj, Rusiji, Francuskoj, Engleskoj, Turskoj i drugim mjestima - imao priliku i iskoristio je da ostavi duboki trag i uticaj na te narode. Zbog toga je kod mnogih novijih islamskih mislilaca postao veoma cijenjen i poštovan. Nazivan je putujućom živom bakljom arapsko-islamskog svijeta od koje će strepjeti kolonijalistička Britanija kao i druge izrabljivačke zemlje. ${ }^{4}$

Druga polovica devetnaestog vijeka je jedan od veoma teških i nezgodnih perioda koji su zadesili islamski i arapski svijet. Bilo je to vrijeme kada su moćne sile Zapada iskoristile svoju moć, a u isto vrijeme nemoć i slabost islamskih zemalja. U tim svojim kolonijalističkim pretenzijama i načinom izrabljivanja najdalje je otišla Engleska. Pod svojom upravom i uz pomoć korumpiranih ljudi na vlasti držali su narod veoma čvrsto koristeći se pri tom svim mogućim sredstvima. Pokušaji da se takve političke neprilike

${ }^{4}$ Vidi: Ahmed Smajlović, "Islamska misao", br. 37, Republičko starješinstvo Islamske zajednice BiH, Hrvatske i Slovenije, Sarajevo, januar 1982. godine, str. 9. 
promijene veoma brzo su bivali osujećeni i sputavani. Da bi se što bolje učvrstili i bili dominantni nad porobljenim narodima, Englezi su kroz taj narod proturili neke nove ideje i shvatanja ne bi li na taj način narod "zaboravio" da se digne protiv okupatora. Tako su takvim idejama nasjeli $\mathrm{i}$ mnogi svršenici fakulteta $\mathrm{i}$ profesori $\mathrm{u}$ Indiji prihvativši ideju o naturalizmu. Za vrijeme svog posljednjeg boravka u Indiji, Afgani se susreće sa takvim ljudima, te odlučuje da napiše kritiku na to novo učenje. Original toga djela nastao je na perzijskom jeziku ${ }^{5}$, a njegov učenik i poštivalac Muhammed Abduhu ga prevodi na arapski.

Djelo Erreddu ala eddehrijin Afgani piše znajući da je ideja o naturalizmu taktika Engleza kako bi se narodi Indije pomirili s činjenicom da slijepo budu pokorni sudbini koja ih je zadesila. ${ }^{6}$ Raspravljajući o problemima koje nudi naturalizam, Afgani kroz svoje djelo ukazuje na mnoga od njih, od kojih posebno možemo izdvojiti ova tri: društvena uloga i mjesto religije, njena uslovljenost i njena opća nužnost. ${ }^{7}$

Govoreći o ovome veoma značajnom pitanju Džemaluddin smatra da jedino religija osigurava ljudskoj zajednici tri glavna elementa, a to su: živost - vitalnost, sigurnost i pravda. Materijalizam ne može čovjeku dati ono što mu daje vjera, npr. sigurnost, strpljivost, smirenost i tome slično. Čovjek posjeduje strasti koje se ne mogu obuzdati, a priroda nam sama od sebe nije dala određeni način na koji se to može učiniti, sem sljedećih:

a) snagom oružja ili drugom silom, ali to vodi proljevanju krvi i uništenju;

b) pomuću ljudske svijesti, a vidjeli smo da je i ona ograničena konvencijama i običajima pa nema neko generalno, opće mjerilo, i

c) državnim aparatom - vladom, a ona poznaje samo ono što čovjek kao (ne)prijatelj društva očigledno ispoljava, dok se skrivena skretanja ne mogu pratiti, a ponekad su i sami ti koji prave nered.

\footnotetext{
5 Fethi, Remli: ''El-Burkanus-sairu', Dž. El-Afgani, Darus-sekafeti, Kairo, 1966, str. 95.

${ }^{6}$ V. Abdulkadir El-Magrebi: ''Džemaluddin el-Afgani', Darul-Mearifi , Kairo, 1968, str. 70.

${ }^{7}$ Fethi Remli, str. 192.
} 
d) Preostalo je, dakle, samo jedno rješenje, a to je vjera $u$ Sveobuhvatnog Stvoritelja - Gospodara nagrade i kazne u Vječnom životu i povinovanje Njegovom zakonu.

U objašnjenju ove posljednje postavke Afgani kaže: "Nećeš vidjeti u trima religijama (judaizmu, kršćanstvu i islamu) ono što se ne slaže za korist čitavog čovječanstva. Naprotiv, svaka podstiče svoga sljedbenika da čini dobro svome bratu i bližnjem, a sprečava ga od lošeg čina prema bilo kome drugom /.../. Što se tiče razilaženja sljedbenika vjera, tome ni jedna vjera ne uči, niti tome ima traga $u$ njihovim knjigama, nego je to djelo nekolicine vjerskih vođa koji ništa drugo nego trguju vjerom /.../. A ona, vjera, prava je bit naroda i izvor sreće za čovjeka. Istinska civilizacija je ona koja se bazira na učenju, moralu i vjeri, a ne samo na materijalnim dostignućima, podizanju velikih gradova, akumulaciji bogatstva ili usavršavanju mašina za ubijanje i uništavanje." 8

\section{Afganijev oslonac na snagu imana}

Za Afganija su glavni izvori svekolikog napretka bili Kur'an i Sunnet. Nije bio filozof kao što je Platon u antičkoj ili u islamskoj filozofiji Ffarabi, koji se povukao u osamu da bi tako na papiru konstruisao idealnu državu. Džemaluddin je svoju filozofiju unosio neposredno u život, u mase, nastojeći tu svoju misao primijeniti $u$ životnoj zbilji. Ovaj slobodni mislilac i misaoni buntovnik, oslobođen je od svih ograničenja, kako geografskih, političkih, vjersko-sektaških, tako i dekadentnošću nametnutih ograničenja u poimanju i razumijevanju islamske misli i misli svijeta uopće. On se nije ograničio samo na jedno polje, niti je svoju aktivnost sveo na jedno geografsko područje. Njegova je pronicljiva misao zahvatila najrazličitije probleme svoga vremena i bila je okrenuta problemima sveukupnog islamskog svijeta.

Kao što je bio protiv podijeljenosti, Džemaluddin je bio i protiv svake vrste sektaštva u vjeri. Nije pripadao ni jednom mezhebu, a od svakog je uzimao ono što se slagalo s njegovim uvjerenjem.

${ }^{8}$ V. Bilalić, Rešid: 'Preporod', br. 8, Starješinstvo IZ-e BiH, Hrvatske i Slovenije, Sarajevo, 15. april, 1982. god., str. 7. 
Njegov imam bio je Kur'an. Iako je bio naklonjen tesavufu, ni prema kome nije bio isključiv.

Svojom dubokom islamskom i revolucionarnom mišlju smetao je kako stranim kolonizatorima i neprijateljima, tako i svim korumpiranim ljudima od vlasti u islamskom svijetu. Predstavljao je strah za sve one koji su bili najpozvaniji da se životom i djelom dokažu kao sljedbenici islama, a oni to ne čine. Tako mu se jednom prilikom sultan Abdul-Hamid, halifa muslimana toga vremena, osjećajući strahopoštovanje prema Afganiji i bojeći se da on ne otkrije istinu o njegovoj vladavini, obraća riječima:

"O šejhu, zašto, naprimjer ne ideš u Japan, pa da tamo pozivaš njegov narod u islam, jer taj narod traga za pravom vjerom?"

A ovaj učenjak i revolucionar mu odgovori kontra pitanjem:

"Da li da idem u Japan i pozivam njegov narod u islam onakav kakav je u islamskim zemljama?"

Sultan se začudio ovakvom odgovoru, pa mu se opet obrati:

"O šejhu, kaži mi razliku o kojoj si maločas govorio i reci mi nešto u vezi s tim i pozivanjem japanskog naroda u islam!"

Afgani mu odgovori:

"Ako bih japanski narod pozivao u islam onakav kakav islam doista i jeste, rekao bi mi: 'Idi ti, čovječe, pa pozivaj svoj narod na te principe, pa ako bude on to prihvatio, onda dođi i pozivaj nas u tu vjeru', a ako bih ga pozivao na islam onakav kakav se primjenjuje u našim zemljama, onda bi mi sigurno rekao da japanski narod nema nikakve potrebe za takvom vjerom i da je za njega bolje da ostane bez jedne takve vjere."'

Iako možda ne bi ni trebao komentar na ovaj veoma smion dijalog između halife i ovog islamskog mislioca, možemo se poslužiti još jednim, dodatnim objašnjenjem samog Afganija. Naime, on kaže da, ako želimo nekog danas pozvati u islam, potrebno je, prije svega, da mu jasno damo na znanje da mi nismo pravi muslimani - da se potpuno ne pridržavamo islamskih principa. ${ }^{10}$

Zbog svega toga Afgani je nastojao svim raspoloživim sredstvima da osvijesti narod i da mu ukaže na sve nedostatke i način da se izvuče iz takve zaostalosti. Svojim životnim iskustvom i putovanjima bio je upoznat i sa trenutnom (tada) situacijom u svijetu,

\footnotetext{
${ }^{9} \mathrm{~V}$.: Islamska misao, br. 37, str. 12 .

${ }^{10}$ V.: 'Dž.El-Afgani' - Magrebi, str. 60.
} 
pa je i mogao tako nešto konstruktivno ponuditi svojim narodima. Probijajući se svukuda i tražeći sve ono što bi moglo koristiti novoj islamskoj misli, čak se našao i u masonskoj loži koja je djelovala u Kairu, služeći se veoma privlačnom parolom francuske revolucije sloboda, bratstvo, jednakost. Međutim, on ubrzo otkriva da je ta parola samo fasada iza koje se kriju sasvim druge namjere. ${ }^{11}$ Napuštajući masonsku ložu Afgani je iz nje tada izvukao elitu tadašnjeg egipatskog društva, sa kojom osniva Istočnu nacionalnu ložu iz koje su kasnije izašli vođe Urabijeve revolucije, a među njima i sam Ahmed Urabi. Nažalost, ovo će kasnije poslužiti Afganijevim neprijateljima da ga optuže za nevjerstvo.

U buđenju i širenju islamske misli on govori i nastoji da opravda upotrebu razuma kojeg nam je dao Allah dž.š. jer, On nas na više mjesta u Kur'anu a.š. poziva na upotrebu uma. Zbog toga je Džemaluddin i bio mišljenja da vrata idžtihada nisu zatvorena. Ne poričući i ne umanjujući zasluge Ebu Hanife, Malika, Šafije i Ibn Hanbela kaže da oni nisu dali konačnu riječ u poimanju Allahovih dž.š. tajni, nego da je to samo kap u moru Njegova bogatstva. ${ }^{12}$ Stoga je potrebno unijeti nove napore za što bolje i jasnije objašnjenje islamskog učenja.

Među mnogobrojnim prenosiocima i komentatorima Afganijevih ideja i shvatanja je i Muhammed Selam Medkur, koji ga u svom djelu posvećenom Afganiji poredi sa Martinom Luterom, reformatorom u kršćanskoj religiji.

Tadašnja uspavanost islamskog življa našem je piscu mnogo smetala budući da je to stanje u kojem je veoma pogodno mutiti čistotu islama. Pasivne umove bilo je nužno aktivirati, kako kaže Džemaluddin, i učvrstiti ih u čistom tevhidu. Čovjek nikada ne smije dozvoliti da se poljulja osnovni temelj islama - vjerovanje u Jednog i Jedinog Allaha dž. ̌̌. - tevhid.

Iako nije citiran ajet u kojem Uzvišeni Allah govori da su svi ljudi stvoreni od jednog muškarca $\mathrm{i}$ od jedne žene, te da su prema tome braća i da je kod Allaha dž.š. najbolji onaj koji je najbogobojazniji, Afgani ističe da je islam taj koji briše sve rodovske, klasne i druge razlike među ljudima. Vrijednost čovjeka određuje se samo po stepenu njegovog umnog, duhovnog i vjerskog dostignuća.

${ }^{11}$ V.: 'Preporod', br. 7, 1982, str. 5.
${ }^{12}$ V.: 'Nabigatuš-šerk', str. 101, 102. 
Uz to, čovjek prilikom svojih tvrdnji mora da govori samo jasnim dokazom, jer u protivnom javlja se sumnja u ispravnost takvih tvrdnji.

I to je bio jedan od razloga što su Afganijevoj misli i djelu mnogi islamski i neislamski filozofi odali puno priznanje i poštovanje. O tome nam, možda, najbolje svjedoči pojava njegovih mnogobrojnih sljedbenika, pa čak i dan-danas, onih koji vide rješavanje nekih pitanja baš onako kako ih je on postavio. U tom pogledu za njega se može reći da zauzima veoma važno mjesto u historiji Istoka, ponajprije zbog svog ogromnog zalaganja za slobodu porobljenog svijeta, te da je on sam njen prvi šehid.

Afganijeve mudre izreke i drugi o njemu ${ }^{13}$

"Čovjek je najveća tajna u kosmosu, nejasne i skrivene tajne prirode

on će umom svojim razotkriti, i postići će znanjem i oslobođenim umom ostvarenje svojih pretpostavki i vidjeti da pretpostavke koje su nemoguće bile odjednom mogućim postadoše."

$* * * * *$

"Ako je istina da ima stvari koje nam niko ne dariva, onda su najveće među njima - sloboda i nezavisnost."

$* * * * *$

"Da neko brani svoju domovinu, prirodni je zakon i životno pravilo za potrebe koje priroda nameće kroz instikte, kao što su potreba za hranom $i$ vodom. I nikoga ne treba hvaliti ako se pokorava tim instinktima."

$* * * * *$

"Pod pojmom izdajica mi ne mislimo na osobu koja proda svoju zemlju za novac i preda je neprijatelju uz veliku ili malu cijenu - a

${ }^{13}$ Citati su korišteni iz pomenute literature i izvora 
svaka cijena za koju se proda zemlja je mala - nego je stvarni izdajica svaka osoba koja je odgovorna za neprijateljsku stopu na tlu njene zemlje, ko dozvoli neprijatelju da učvrsti svoju nogu na njegovoj zemlji, a on je u stanju da to spriječi."

$* * * * *$

"Nema stida za jednu malu naciju, brojčano nejaku, ali duhovno jaku, ako bude pobijeđena oružanom snagom veće i jače nacije. Ali, sramota koju vrijeme neće izbrisati je ako ta nacija ili jedan od njenih članova, ili pak grupa budu trčali da poture svoje vratove pod neprijateljski jaram, svejedno da li to čine iz nepromišljenosti $u$ upravljanju poslovima ili iz želje za prolaznim koristima, jer takvi postaju uzročnicima svoje vlastite propasti."

$* * * * *$

"Ja sam lav koji ne ostaje bez plijena ma gdje krenuo", rekao je Džemaluddin napuštajući Egipat pod policijskom pratnjom.

$* * * * *$

"Ja sam kao orao u letu koji prostranstvo ovog širokog svijeta vidi skučenim za njegov let. I zaista vam se čudim kad me želite zarobiti u ovaj tijesni i maleni kafez!"

$* * * * *$

"Smatram, Vaša Visosti, da je vladaru bolje da mu milioni njegovih podanika budu prijatelji nego neprijatelji koji samo čekaju pogodnu priliku."

$* * * * *$

"Od kada vi, Englezi, stekoste svojinsko pravo nad Sudanom, pa da možete postaviti njegovom narodu koga vi hoćete i želite za sultana?" 
"Seljak i radnik u kraljevini, Vaša ekselencijo, korisniji je od Vaše Visosti i Vaših prinčeva. Bez sumnje ste, Vaša ekselencijo, čuli ili čitali o narodu koji je mogao živjeti bez kralja, a da li ste vidjeli kralja koji je živio bez naroda i podanika?!"

*****

"Misticizam nije samo isključivo u islamu, nego ga prepoznaju i sve druge vjere. U Tevratu i Indžilu imamo izraza čije pravo značenje nije u zahir (pojavnom) obliku. “

*****

"O dervišu, čiji je život prolazan,

čega se plašišs?!

Bestraga i ti i strah tvoj!

Ne boj se sultana, nit se plaši šejtana,

Budi mudar, vidjet ćeš svijet ovaj igračkom,

Ne budi dijete usplahireno!

Svejedno je meni dugo ili kratko život potrajao,

Namjera mi je cilj dostići,

A onda ću reći-Pobijedih, Gospodara mi Kabe!"

*****

"Čovjek nema ni jednog organa da se pokreće bez cilja. Svaki pokret kojeg učini, pa iako ne zna cilj, on ga učini svjesno ili nesvjesno."

*****

"Problemi neznanja kod čovjeka su brojniji od problema onoga što zna, a ljudski vijek je kratak da sazna sve ono što želi."

*****

"U najgore ljude se ubraja onaj koji želi tuđu smrt da bi on živio, dok je najčasniji onaj koji je spreman na svoju smrt da bi drugi živio." 
"Oslonac na sebe i pouzdanje u Allaha Uzvišenog najveći su faktori za uspjeh."

$$
* * * * *
$$

"Ko se umislio da je savršen, izdaće ga njegova djela."

$* * * * *$

"Najteži je pokrivač onaj kojim zavidnik želi pokriti uspjeh drugoga."

***** $*$

"Pogrešno je shvatanje onoga koji smatra da je bolji od drugoga samo zato što je stariji i ima višse sijedih."

$* * * * *$

"Kukavičluk ne obogaćuje, niti hrabrost može osiromašiti."

$* * * * *$

"Istinu izmišljotine ne mogu nadvladati."

*****

"Pametan je svjestan svoje ograničene moći, ali se trudi da djeluje."

*****

"Nema dobra u onome insanu od koga je hajvan bolji."

$* * * * *$

"Niko ne umire za svoj narod, a da on neće živjeti u njemu." 
"Nema pravog naroda bez morala, niti pravog morala bez prave ideologije, niti ideologije ako nije razumljiva."

*****

"Najveća vrijednost jednog naroda je njegov moral."

*****

"Veća je potreba voditi računa o svom zdravlju nego o svom imetku."

*****

"Dva pametna mudraca u jednom milionu ljudi bolja su od hiljadu onih koji su umišljeni da su pametni i mudri."

$* * * * *$

"Mnogo je onih koji istražuju mudrost, ali je malo onih koji djeluju. Odnosno, puno je onih koji pametuju, ali je malo onih koji uistinu djeluju."

*****

"Prava moralna ličnost nikada nije egoista."

$* * * * *$

"Ko želi da živi, neka bude spreman na žrtvu za svoj narod."

*****

"Jedno pravo djelo je jače na vagi od hiljadu praznih priča."

$* * * * *$

"Snaga žene je u njenoj nježnosti."

***** 
"I kamen je bolji od čovjeka koji sjedi bez razloga i traži sebi takvog (ljenčinu)."

$* * * * *$

"Učenjake jednog vremena izbacuje samo vrijeme, a vođe izbacuju nevolje."

$* * * * *$

"Onaj ko je u pravu - snažan je, makar bio i slabić, a onaj ko nije u pravu - lažac, slabić je, pa makar bio fizički snažan."

$$
* * * *
$$

"Čovjeku od pera nije potreban štap."

$$
* * * * *
$$

"Čovjek kome se otvore vrata, pa ne uđe, bolje je da se vrati." (neka ne stoji pred vratima)

$* * * * *$

"Ko prešuti svoje pravo, bit će ugrožen."

$* * * * *$

"Mala je korist kod istine koju ne podupire snaga."

$* * * * *$

"Ne može se uvijek držati onoga da se sa malo priče može puno reći."

$* * * * *$

"Ono što nedostaje Orijentu su snažni i pravedni vladari, a problem leži u tome što ima pravednih - ali slabih, te snažnih - al' nepravednih." 
"Napuštanje onoga što je dovelo do uspona, vodi ka padu i nesreći."

***** $*$

"Ko smatra da ne postoji drugi svijet osim ovoga, izgubiće $i$ jedan $i$ drugi, tj. i ovaj i budući."

$* * * * *$

"Siromah učenjak je bogat zbog svoga znanja, a bogati neznalica je siromašan zbog svoga neznanja."

*****

"Kad zavlada neznanje, nastat će ružno stanje (vrijeme)."

*****

"Najgora bolest muslimana Istoka je njihovo razilaženje o pitanju jedinstva $i$ jedinstva u razilaženju, jer se dogovaraju da se ne dogovore."

*****

"Odakle smjelost poricati Stvoritelja Velikog kad čovjek zna da će skončati i biti pojeden od strane malog crva."

*****

"Povlačenje pametnog ispred džahila - neznalice bolje je nego se s njime natezati."

*****

"Nekad je i znanje bilo smješteno u glavama i prsima, a sada se sakrilo pod džubu (odjeću) i u olovke." 
"Ko nije u stanju popraviti sebe, neće biti u stanju ni druge popraviti."

*****

"Narod koji prigovara vladaru u tajnosti, a hvali ga u javnosti, ne zaslužuje da živi."

*****

"Najgora vremena su ona u kojima džahili - neznalice kolo vode, a učenjaci šute."

*****

"Biti hamal (nosač) i nositi tovare $u$ želji za halal zaradom bolje je nego oslanjati se na skriveno zlato."

$* * * * *$

"Čovjek odbija da prihvati sve ono što ga ne zadovoljava, a voli sve ono čemu ga, upravo, strast vodi."

$* * * * *$

"Ako bih rekao da je ono što mu je Allah podario (Afganiji) od intelektualnih moći i pronicljivosti najviše što je dato nekima, izuzev poslanika, ne bih pretjerao. Kao da je univerzalna Istina koja se objavljuje u svakom uти kako ти dolikuje, ili duhovna snaga koja se ukazuje pred svakom vizijom u obliku koji joj odgovara!" - kaže Muhammed Abduhu.

$* * * * *$

"On mi je podario život kojeg dijelim sa Muhammedom, a.s., $i$ Ibrahimom, a.s., i sa evlijama, a otac mi je podario život kojeg dijelim 
sa braćom Alijem i Mahrusom. Od Afganija sam stekao mudrost kojom ljudska srca preobraćam i umove prosvjetljavam!" (Abduhu)

$* * * * *$

"Afganiju po oštrini njegove revolucionarnosti $i$ nepokolebljivosti možemo porediti sa Robespijerom/Robespierreom, po dubini $i$ privrženosti revolucionarnoj islamskoj ideologiji sa Maroom $u$ buržoaskoj revoluciji, po snazi i moći uticaja pokretanja masa sa Trockim, po snazi odlučnosti, organizovanosti $i$ nesalomljivosti sa Lenjinom u velikoj Oktobarskoj proleterskoj revoluciji." (Vahid elMisri)

$* * * * *$

"Veza koja je sjedinjavala muslimane počinje da slabi od vremena abasijskih halifa koji su se počeli zadovoljavati titulom halife, a prestali biti učenjaci, prekidajući time tradiciju idžtihada. I danas još vidimo neke muslimanske upravljače koji daju slobodnu ruku strancima da upravljaju poslovima u njihovim državama, pa čak $i$ u njihovim vlastitim kućama i tako požuruju stranu upravu nad svojim vratovima. Evropljani, pohlepni na muslimanske zemlje, žele razoriti njihovo vjersko jedinstvo, a tome doprinosi unutarnja nesloga muslimanskih zemalja."

*****

"Ko se odvikne od nečega, živi bez toga."

*****

"Onim očima kojim gledaš narod, narod gleda tebe."

*****

"Mojoj djeci i djeci drugih, onima koji traže više od herojstva, predstavljam heroja kojeg u historiji nema sličnog." (Abduhu) 
"Bez ikakve dvojbe, gospodin Džemaluddin Afgani je najveći islamski misionar druge polovice devetnaestog stoljeća. Aktivno je djelovao protiv sivila autokracija i pokvarenih vlasti koje su tada dominirale $u$ arapskom svijetu, a ništa bolje stanje nije bilo ni u Otomanskom carstvu." ( Hamilton A. Gib, engleski orijentalista)

$* * * * *$

"Doista je Džemaluddin Afgani jako puno ostavio traga na egipatsko buđenje. Sa svojim učenikom Muhammedom Abduhuom posijao je sjeme čiji su korijeni duboko $i$ čvrsto ušli u zemlju $i$ sada daju plodove, te postepeno nadahnjuje $i$ druge zajednice. Pod njegovim utjecajem nastale su mnoge grupacije na polju nauke i politike a većinu svojih snažnih ideja je iznio u časopisu 'Urwetul-wuska'. Želio je istaći da islam nije samo zbirka vjerskih obreda nego jedna savršena životna civilizacija. Zbog toga je misija Afganija bila čvrsto vezana za istinsku islamsku da'wu (misionarstvo), kako bi izrazio ispravno učenje kojim je moguće uticati na buđenje i osvješćenje muslimana." (Kampffmeyer, njemački orijentalista)

Zaključak

Govorismo o čovjeku kakav se rijetko rađa i oko kojeg su se i narodi dviju država sporili - čiji je on državljanin. Smatrajući da ovakvi velikani prevazilaze okvire bilo koje nacije ili države, možemo reći da je on „naš“, te da pripada cijelom ljudskom rodu. Njegove mudre riječi i borba protiv nepravde i svih drugih vrsta zala svrstavaju ga u plejadu svjetskih filozofa i revolucionara. Zato ne bi trebalo da čudi to što ga je „prozvao“ i reis dr. Mustafa ef. Cerić na Svjetskoj islamskoj konferenciji u Istanbulu prošle godine, govoreći da trebamo novog Afganija.

- Mislim da trebamo novog Afganija koji će nam kazati kako da postanemo svjetlo koje će široko sijati i osvjetljavati svoje okruženje i drugima tu svjetlost darivati. Vjerujem da ova konferencija treba biti upravo to: Novo svjetlo za muslimane Evrope. Neka nam dragi Bog pomogne da to postignemo - rekao je 
dr. Cerić (preneseno kao vijest u Dnevnom avazu, 3. jula 2006. godine).

\section{Literatura}

1. Abdulkadir El-Magrebi: „Džemaluddin El-Afgani“ - DarulMearifi, Kairo, 1968. god.

2. Fethi Remli: „El-Burkanus-sairu, Dž. El-Afgani“ - Darussekafeti, Kairo, 1966. godine

3. Muhammed Seid Abdulmedžid: „Nabigatuš-šerk es-sejjid Džemaluddin El-Afgani“" - Darul-kitabil-arebi, Kairo, 1967. godine

4. Selam Medkur: „Džemaluddin El-Afgani““, El-Medžlisul-eala lišuuni islamijjeti, vizaretul-evkaf, Kairo, 1962. godine

Periodika

5. „ISLAMSKA MISAO“, Sarajevo, januar, 1986. godine

6. „PREPOROD“, Islamske informativne novine, Sarajevo, od 1.3.1982. godine

7. „PREPOROD“, Sarajevo, od 1. 4. 1982. godine

8. „PREPOROD“, Sarajevo, od 15. 4. 1982. godine 
DOC. DR. IZET TERZIĆ. SENIOR LECTURER

\section{JAMALUDIN AL AFGHANI - REFORMATOR OF ISLAMIC THOUGHT}

\section{SUMMARY}

The words of Messenger of Allah (SAWS): "Scholars are heirs of prophets» are fully confirmed in character and work of Jamaludin Afghani. From his early childhood he showed interest for science and philosophy. This was the reason that be became powerful and influential personality that thoroughly examined power - holders and scholars of his time. He used to enter bravely into discussions with authorities and scholars. On the way of truth, he was not spearing anyone, not even himself, therefore we can say that he laid down his life for this noble cause.

Although he was a severe critic of political and religious leaders, in Islamic and non Islamic milieus, he was fully respected and honoured. The noble cause can be achieved only with wise moves and the help of the Lord of worlds.

Afghani will be remembered as the brightest torch that appeared in the second half of 19th century and his wise sayings are still fresh and inspiring. 
الدكتور عزت تززينش

\section{جمال الدين الأفغاني - مجدد الفكر الإسلامي}

\section{الملخص}

إن شخصية وعمل جمال الدين الأفغاني هي مصداق حديث رسول اله صلى اله عليه

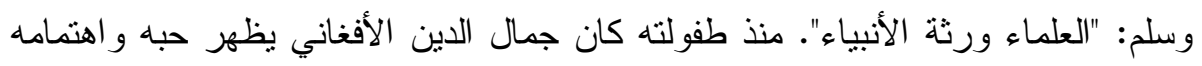
بالعلم و الفلسفة ومن ذلك نشأت شخصية قوية ومؤثرة قدمت للعقل السليم تحت عدسات التكبير حكام و علماء ذلك الزمان. لقد كان يحاور كل عظيم في الحكم و العلم بشجاعة، ولم يكن بستثني أحداً، وحتى نفسه، في سبيل الحق ولذلك يمكننا القول إنه ضحّى بحياته في سبيل تلك الأهداف العالية. و إن كان شديد النقد للزعماء السياسيين و الدينيين، سواء في البلاد الإسلامية و غير ها، فإنه كان يتمتع بالاحتر ام و الثقدير من طرفهم.

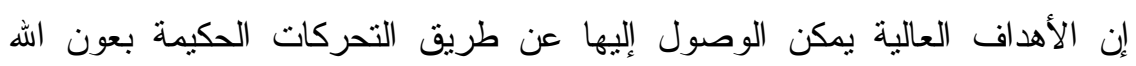

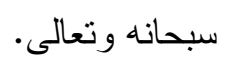
سيظل جمال الدين الأفغاني في الذاكرة شعلةً مضيئةً ظهرت في المنتصف الثاني من القرن التاسع عشر ، و إلى الآن لم تفقد كلماته الحكيمة شيئاً من قوتها و أهميتها. 